\title{
Profil pasien preeklamsia berat dan eklamsia di ICU dan HCU RSUP Prof. Dr. R. D. Kandou Manado
}

\author{
${ }^{1}$ Vania N. Patty \\ ${ }^{2}$ Diana Ch. Lalenoh \\ ${ }^{2}$ Debby D. Wuisan
}

\author{
${ }^{1}$ Kandidat Skripsi Fakultas Kedokteran Universitas Sam Ratulangi Manado \\ ${ }^{2}$ Bagian/SMF Anestesiologi dan Terapi Intensif RSUP Prof. Dr. R. D. Kandou Manado \\ Fakultas Kedokteran Universitas Sam Ratulangi Manado \\ Email: vanianita03@gmail.com
}

\begin{abstract}
Preeclampsia was defined as hypertension in pregnancy that occurs after 20th weeks of pregnancy meanwhile eclampsia is the new onset of a grand mal seizure activity and is one of the complications of preeclampsia. Preeclampsia and eclampsia are still the major causes of high maternal and infant mortality in Indonesia $(1.5 \%-25 \%)$. Severe preeclampsia becomes an indication of obstetric patients to be admitted to ICU. This study was aimed to obtain the profile of patients with severe preeclampsia and eclampsia admitted to the ICU and HCU Prof. Dr. R.D. Kandou Hospital. This was a descriptive retrospective study. Data were obtained from the medical records of patients admitted to the ICU and HCU from September 2014 to August 2016. There were 33 patients that met the inclusion criteria consisted of 11 patients (33\%) with severe preeclampsia and 22 patients $(67 \%)$ with eclampsia. Most patients were aged $\leq 25$ years and the median length of stay in this study was 2 days. HELLP syndrome was found in 9 patients (27.3\%) and DIC in 1 (3\%) patient. There were five patients with ventilator and three patients died due to eclampsia. Conclusion: Most patients in this study were patients with eclampsia and the mortality rate was $9.1 \%$.
\end{abstract}

Keywords: severe preeclampsia, eclampsia, ICU, HCU

\begin{abstract}
Abstrak: Preeklamsia didefinisikan sebagai hipertensi dalam kehamilan yang terjadi setelah minggu ke- 20 kehamilan, sedangkan eklamsia adalah onset baru aktifitas kejang grand mal dan merupakan salah satu komplikasi dari preeklamsia. Preeklamsia dan eklamsia masih menjadi penyebab utama tingginya angka kematian ibu dan bayi di Indonesia (1,5\%-25\%). Preeklamsia berat menjadi indikasi pasien obstetri masuk ke ICU. Penelitian ini bertujuan untuk mengetahui gambaran pasien preeklamsia berat dan eklamsia yang dirawat di ICU dan HCU RSUP Prof. Dr. R.D. Kandou. Jenis penelitian ialah deskriptif retrospektif. Data diperoleh melalui data rekam medik pasien yang dirawat di ICU dan HCU periode September 2014 - Agustus 2016 dan didapatkan sebanyak 33 pasien yang memenuhi kriteria inklusi. Total pasien preeklamsia berat ialah 11 orang (33\%) dan eklamsia sebanyak 22 orang $(67 \%)$. Usia $\leq 25$ tahun ialah usia terbanyak dan median lama rawat dalam penelitian ini ialah 2 hari. Kejadian HELLP syndrome pada kasus ini sebanyak 9 orang (27,3\%) dan DIC sebanyak 1 orang (3\%). Pasien dengan ventilator sebanyak 5 orang dan pasien yang meninggal akibat eklamsia sebanyak 3 orang. Simpulan: Dalam penelitian ini pasien terbanyak ialah pasien eklamsia dengan angka kematian 9,1\%.
\end{abstract}

Kata kunci: preeklamsia berat, eklamsia, ICU, HCU 
Preeklamsia didefinisikan sebagai hipertensi dalam kehamilan yang terjadi setelah minggu ke-20 kehamilan. ${ }^{1}$ Eklamsia adalah onset baru aktifitas kejang grand mal dan merupakan salah satu komplikasi dari preeklamsia. $^{2}$ Secara global, preeklamsia dan eklamsia menyebabkan 10-15\% dari kematian ibu atau diperkirakan lebih dari 50.000 perempuan di seluruh dunia meninggal setiap tahunnya karena preeklamsia/ eklamsia. ${ }^{1,3,4}$ Sebagian besar kematian di negara-negara berkembang disebabkan oleh eklamsia, sedangkan di negara-negara maju komplikasi dari preeklamsia yang lebih sering menyebabkan kematian. ${ }^{5}$

Insiden preeklamsia bergantung pada besar populasi yang diteliti dan definisi dari preeklamsia itu sendiri. Beberapa studi melaporkan insiden preeklamsia dari berbagai tempat: di Israel insiden preeklamsia 2,8\%, Skotlandia 5,8\%, Australia $14,1 \%$, dan Seattle 5\%. ${ }^{4}$ Studi lain melaporkan insiden eklamsia dari Amerika Serikat sebesar 1 dalam 3.250 kehamilan; dari UK 1 dalam 2.000 kehamilan; dari Dublin 1 dalam 2.500 kehamilan; dari Skandinavia 1dalam 2000 kehamilan; dan dari Belanda 1 dalam 1600 kehamilan. ${ }^{5}$ Angka kejadian preeklamsia di Asia yaitu 1,6-3,6\% dalam kehamilan. Preeklamsia dan eklamsia masih menjadi penyebab utama tingginya angka kematian ibu dan bayi di Indonesia dengan angka kejadian berkisar 1,5-25\%. ${ }^{7,8}$

Di dunia belahan Barat dan Asia, preeklamsia menjadi salah satu penyebab utama masuknya pasien di ICU selain perdarahan dalam kehamilan. Preeklamsia berat menjadi indikasi pasien obstetri masuk ke ICU karena berisiko menyebabkan komplikasi berupa kegagalan multiorgan dan kejang. Indikasi pasien di ICU dengan preeklamsia berat umumnya memiliki komplikasi seperti disfungsi neurologik (eklamsia), disfungsi hati dan ginjal, edema paru, HELLP syndrome dan atau Disseminated Intravascular Coagulation (DIC) ${ }^{9-11}$

Berdasarkan uraian di atas, penulis tertarik melakukan penelitian untuk mengetahui profil pasien preeklamsia berat dan eklamsia yang dirawat di ICU dan HCU RSUP Prof. Dr. R. D. Kandou Manado.

\section{METODE PENELITIAN}

Jenis penelitian ini ialah deskriptif retrospektif dengan metode pusposive sampling. Data diambil dari data rekam medis pasien yang dirawat di ICU dan HCU periode September 2014 sampai Agustus 2016. Subjek penelitian ialah semua pasien preeklamsia berat dan eklamsia. Kriteria inklusi ialah pasien yang terdiagnosis preeklamsia berat dan eklamsia sesuai protokol SOP bagian Obstetri-Ginekologi dengan rentang usia 18-45 tahun. Data yang dikumpulkan meliputi usia, lama rawat pasien, angka kejadian HELLP syndrome, angka kejadian DIC, penggunaan ventilator, dan angka kematian. Data diolah dengan program microsoft excel.

\section{HASIL PENELITIAN}

Berdasarkan penelitian yang telah dilakukan dengan mengambil data rekam medik pasien preeklamsia berat (PEB) dan eklamsia di ICU dan HCU RSUP Prof. Dr. R. D. Kandou dalam periode September 2014 sampai Agustus 2016, diperoleh sampel sebanyak 33 orang pasien yang memenuhi kriteria inklusi (Gambar 1).

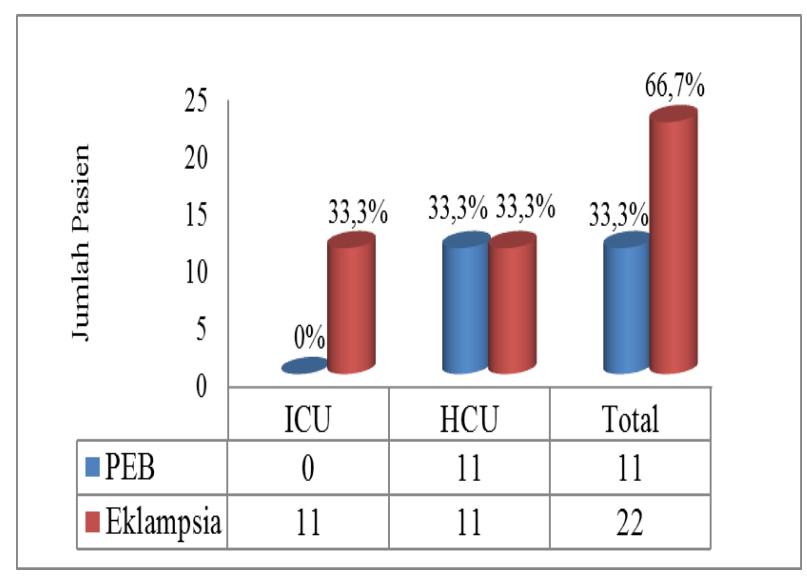

Gambar 1. Sebaran pasien PEB dan eklamsia di ICU dan HCU

Gambar 1 menjelaskan jumlah pasien PEB dan eklamsia yang dirawat di ICU dan 
HCU dalam periode 2 tahun. Terdapat 22 pasien $(66,7 \%)$ eklamsia dan 11 pasien $(33,3 \%)$ PEB.

Tabel 1 menunjukkan sebaran pasien PEB dan eklampsia di ICU dan HCU menurut usia. Pada usia $<25$ tahun didapatkan 12 pasien $(36,4 \%)$ dengan 4 pasien $(12,1 \%)$ PEB dan 8 pasien $(24,2 \%)$ eklamsia. Pada usia 25-34 tahun didapatkan 11 pasien $(33,3 \%)$ dengan 6 pasien $(18,2 \%)$ PEB dan 5 pasien $(15,2 \%)$ eklamsia. Pada usia $\geq 35$ tahun didapatkan 10 pasien (30,3\%) dengan 1 pasien (3\%) PEB dan 9 pasien $(27,3 \%)$ eklamsia.

Tabel 1. Sebaran pasien PEB dan eklamsia di ICU dan HCU menurut umur

\begin{tabular}{lccc}
\hline $\begin{array}{l}\text { Usia } \\
\text { (tahun) }\end{array}$ & $\begin{array}{c}\text { PEB } \\
\mathbf{n}(\boldsymbol{\%})\end{array}$ & $\begin{array}{c}\text { Eklamsia } \\
\mathbf{n}(\boldsymbol{\%})\end{array}$ & $\begin{array}{c}\text { Total } \\
\mathbf{n}(\boldsymbol{\%})\end{array}$ \\
\hline$<25$ & $4(12,1)$ & $8(24,2)$ & $12(36,4)$ \\
$25-34$ & $6(18,2)$ & $5(15,2)$ & $11(33,3)$ \\
$\geq 35$ & $1(3,0)$ & $9(27,3)$ & $10(30,3)$ \\
Total & $11(33,3)$ & $22(66,7)$ & $33(100)$ \\
\hline
\end{tabular}

Tabel 2 menunjukkan sebaran pasien PEB dan eklampsia di ICU dan HCU berdasarkan lama rawat. Pasien PEB dan eklampsia dalam 1-2 hari didapatkan pasien berjumlah 11 orang $(100 \%)$ dan 22 orang $(100 \%)$ sedangkan untuk 3-4 hari sampai dengan > 6 hari tidak ditemukan pasien PEB serta $>6$ hari masih terdapat 5 pasien eklampsia.

Tabel 2. Sebaran pasien PEB dan eklampsia di ICU dan HCU menurut lama rawat

\begin{tabular}{ccc}
\hline $\begin{array}{c}\text { Lama rawat } \\
\text { (hari) }\end{array}$ & $\begin{array}{c}\text { PEB } \\
\mathrm{n}(\%)\end{array}$ & $\begin{array}{c}\text { Eklamsia } \\
\mathrm{n}(\%)\end{array}$ \\
\hline $1-2$ & $11(100)$ & $22(100)$ \\
$3-4$ & $0(0,0)$ & $14(63,6)$ \\
$5-6$ & $0(0,0)$ & $8(36,4)$ \\
$>6$ & $0(0,0)$ & $5(22,7)$ \\
\hline
\end{tabular}

Tabel 3 memuat data statistik menurut lama rawat dengan rerata keseluruhan 3,42, rerata untuk pasien PEB 1,45 dan pasien eklamsia 4,41. Nilai median ialah 2 hari, lama rawat terbanyak dari pasien ialah 1 hari, lama rawat terpendek dalam penelitian ini ialah 1 hari dan terpanjang ialah 18 hari.

Tabel 3. Data statistik pasien PEB dan eklamsia di ICU dan HCU menurut lama rawat

\begin{tabular}{|c|c|c|}
\hline \multicolumn{2}{|c|}{ Variabel } & Lama rawat (hari) \\
\hline \multirow{3}{*}{ Mean } & PEB & 1,45 \\
\hline & Eklampsia & 4,41 \\
\hline & Total & 3,42 \\
\hline \multicolumn{2}{|c|}{ Median } & 2 \\
\hline \multicolumn{2}{|c|}{ Modus } & 1 \\
\hline \multicolumn{2}{|c|}{ Min } & 1 \\
\hline \multicolumn{2}{|c|}{ Max } & 18 \\
\hline
\end{tabular}

Tabel 4 menunjukkan sebaran pasien PEB dan eklamsia di ICU dan HCU menurut angka kejadian HELLP syndrome. Semua pasien dengan HELLP syndrome merupakan pasien eklamsia dengan jumlah 9 orang $(27,3 \%)$ sednagkan 24 pasien $(72,7 \%)$ lain baik PEB dan eklampsia tidak terdapat HELLP syndrome.

Tabel 4. Sebaran pasien PEB dan eklamsia di ICU dan HCU menurut angka kejadian HELLP syndrome

\begin{tabular}{ccc}
\hline $\begin{array}{c}\text { Pasien ICU } \\
\text { dan HCU }\end{array}$ & $\begin{array}{c}\text { HELLP } \\
\text { Syndrome } \\
\mathrm{n}(\%)\end{array}$ & $\begin{array}{c}\text { Non HELLP } \\
\text { Syndrome } \\
\mathrm{n}(\%)\end{array}$ \\
\hline PEB & $0(0)$ & $11(33,3)$ \\
Eklamsia & $9(27,3)$ & $13(39,4)$ \\
Total & $9(27,3)$ & $24(72,7)$ \\
\hline
\end{tabular}

Tabel 5 menunjukkan angka kejadian HELLP syndrome menurut lama rawat. Pasien dengan HELLP syndrome menurut lama rawat terbanyak didapatkan berada dalam > 6 hari sebanyak 4 pasien $(44,4 \%)$, diikuti dengan 3-4 hari 3 pasien $(33,3 \%)$, serta 1-2 hari dan 5-6 hari sebanyak 1 pasien $(11,1 \%)$.

Tabel 5. Sebaran pasien PEB dan eklamsia dengan HELLP syndrome menurut lama rawat inap di ICU dan HCU

\begin{tabular}{cc}
\hline Lama rawat (hari) & $\begin{array}{c}\text { HELLP syndrome } \\
\mathrm{n}(\%)\end{array}$ \\
\hline $1-2$ & $1(11,1)$ \\
$3-4$ & $3(33,3)$ \\
$5-6$ & $1(11,1)$ \\
$>6$ & $4(44,4)$ \\
\hline
\end{tabular}


Tabel 6 menunjukkan sebaran pasien PEB dan eklamsia di ICU dan HCU menurut angka kejadian DIC 3\% yang berarti hanya terdapat 1 orang pasien eklamsia dengan DIC, dan tidak terdapat pasien PEB dengan DIC.

Tabel 6. Sebaran pasien PEB dan eklamsia di ICU dan HCU menurut angka kejadian DIC

\begin{tabular}{ccc}
\hline $\begin{array}{c}\text { Pasien ICU dan } \\
\text { HCU }\end{array}$ & $\begin{array}{c}\text { DIC } \\
\mathbf{n}(\boldsymbol{\%})\end{array}$ & $\begin{array}{c}\text { Non DIC } \\
\mathbf{n}(\boldsymbol{\%})\end{array}$ \\
\hline PEB & $0(0)$ & $11(33,3)$ \\
Eklampsia & $1(3,0)$ & $21(63,6)$ \\
Total & $1(3,0)$ & $32(97,0)$ \\
\hline
\end{tabular}

Tabel 7 menunjukkan sebaran pasien PEB dan eklampsia di ICU dan HCU menurut penggunaan ventilator. Sebanyak 5 pasien $(15,2 \%)$ yang menggunakan ventilator merupakan pasien eklamsia sedangkan 28 pasien $(84,8 \%)$ tidak menggunakan ventilator.

Tabel 7. Sebaran pasien PEB dan eklampsia di ICU dan HCU beserta menurut penggunaan ventilator

\begin{tabular}{cccc}
\hline $\begin{array}{c}\text { Pasien ICU } \\
\text { dan HCU }\end{array}$ & $\begin{array}{c}\text { PEB } \\
\mathbf{n}(\boldsymbol{\%})\end{array}$ & $\begin{array}{c}\text { Eklamsia } \\
\mathbf{n}(\boldsymbol{\%})\end{array}$ & $\begin{array}{c}\text { Total } \\
\mathbf{n}(\boldsymbol{\%})\end{array}$ \\
\hline Ventilator & $0(0)$ & $5(15,2)$ & $5(15,2)$ \\
Non-ventilator & $11(33,3)$ & $17(51,5)$ & $28(84,8)$ \\
Total & $11(33,3)$ & $22(66,7)$ & $33(100)$ \\
\hline
\end{tabular}

Tabel 8 menunjukkan lama pemakaian ventilator dari kelima pasien dengan HELLP syndrome.

Tabel 8. Sebaran pasien PEB dan eklampsia di ICU dan HCU menurut lama penggunaan ventilator dengan HELLP syndrome

\begin{tabular}{ccc}
\hline $\begin{array}{c}\text { Lama } \\
\text { penggunaan } \\
\text { (hari) }\end{array}$ & $\begin{array}{c}\text { HELLP } \\
\text { syndrome } \\
\mathrm{n}(\%)\end{array}$ & $\begin{array}{c}\text { Non-HELLP } \\
\text { syndrome } \\
\mathrm{n}(\%)\end{array}$ \\
$1-4$ & $1(20)$ & $1(20)$ \\
$5-8$ & $1(20)$ & $0(0)$ \\
$>8$ & $2(40)$ & $0(0)$ \\
Total Pasien & $4(80)$ & $1(20)$ \\
\hline
\end{tabular}

Sebanyak 4 (80\%) pasien yang menggunakan ventilator dengan komplikasi
HELLP syndrome dan lama penggunaan 14 hari sebanyak 1 orang (20\%), 5-8 hari sebanyak 1 orang $(20 \%)$, dan $>8$ hari sebanyak 2 orang (40\%), sedangkan pasien non-HELLP syndrome hanya terdapat 1 pasien (20\%) dengan lama penggunaan ventilator 1-4 hari (Tabel 8).

Tabel 9 menunjukkan sebaran pasien PEB dan eklampsia di ICU dan HCU menurut angka kematian. Jumlah pasien yang meninggal dalam periode September 2014-Agustus 2016 sebanyak 3 orang pasien dengan angka kematian 9,1\%; semua pasien tersebut merupakan pasien eklamsia.

Tabel 9. Sebaran pasien PEB dan eklampsia di ICU dan HCU menurut angka kematian

\begin{tabular}{llc}
\hline $\begin{array}{c}\text { Pasien ICU dan } \\
\text { HCU }\end{array}$ & n & $\begin{array}{c}\text { Angka } \\
\text { kematian }\end{array}$ \\
PEB & 0 & $0,0 \%$ \\
Eklampsia & 3 & $9,1 \%$ \\
Total & 3 & $9,1 \%$ \\
\hline
\end{tabular}

\section{BAHASAN}

Hasil penelitian yang dilakukan, mendapatkan pasien PEB dan eklampsia di ICU dan HCU berjumlah 33 orang selama periode 2 tahun terdiri dari 11 orang $(33 \%)$ pasien PEB dan 22 orang $(67 \%)$ pasien eklamsia. Penelitian Curiel-Balsera et al ${ }^{12}$ mendapatkan 203 pasien PEB dan 16 pasien eklampsia. Hasil yang berbeda mungkin disebabkan adanya perbedaan pada jumlah bed dan indikasi masuk ICU dan HCU.

Menurut usia pasien, dalam penelitian ini pasien PEB dan eklamsia terbanyak berada dalam kelompok usia $<25$ tahun sebanyak 12 orang diikuti dengan usia 2534 tahun sebanyak 11 orang dan $\geq 35$ tahun sebanyak 10 orang. Desalegn dan Haile ${ }^{13}$ mendapatkan pasien PEB dan eklamsia yang dirawat di ICU terbanyak pada kelompok usia 34-38 tahun $(27,1 \%)$ dari 314 pasien. Shamsi et al. ${ }^{4}$ menyatakan bahwa wanita dengan usia pada masa awal reproduktif dan usia $>35$ tahun memegang peranan dalam meningkatkan risiko PEB dan eklamsia. Mengenai perbedaan antara 
ketiga kelompok usia yang tidak jauh berbeda pada penelitian ini mungkin disebabkan adanya faktor risiko lain yang memengaruhi seperti nulipara, hamil kembar, riwayat hipertensi, dan diabetes sebelumnya. $^{8}$

Berdasarkan lama rawat pasien di ICU dan HCU, dalam rentang 1-2 hari pasien yang dirawat masih berjumlah 33 pasien $(100 \%)$. Desalegn dan Haile ${ }^{13}$ juga menyebutkan rerata lama rawat pasien PEB yaitu selama 6 hari dan pasien eklampsia selama 7 hari. Dalam penelitian ini, hasil yang didapat untuk rerata pasien PEB yaitu 1 hari dan pasien eklamsia yaitu 4 hari yang lebih singkat dibandingkan penelitian Desalegn dan Haile. ${ }^{13}$ Kemungkinan adanya komplikasi dan keadaan umum yang buruk menjadi faktor risiko pasien dengan lama rawat lebih panjang.

HELLP syndrome merupakan komplikasi yang dapat terjadi pada PEB maupun eklamsia. ${ }^{10}$ Kansaria dan Parulekar ${ }^{14}$ mendapatkan dari 52 pasien PEB terdapat 5 pasien PEB dengan HELLP Syndrome, sedangkan dalam penelitian Zhang et $\mathrm{al}^{15}$ untuk pasien eklamsia menyatakan bahwa dari 165 kasus eklamsia terdapat 9 pasien $(5,5 \%)$ yang disertai dengan HELLP syndrome. Dari penelitian ini didapatkan bahwa dari 22 pasien eklamsia, terdapat 9 pasien $(27,3 \%)$ dengan komplikasi HELLP syndrome sedangkan dari 11 pasien PEB tidak ditemukan pasien dengan komplikasi HELLP syndrome. Hal ini mungkin disebabkan oleh berbagai hal diantaranya, sosial ekonomi yang lebih rendah dan perbedaan batasan diagnosis PEB dan eklamsia. ${ }^{4}$ Dalam penelitian ini, menurut lama rawat pasien PEB dan eklampsia dengan komplikasi HELLP syndrome, didapatkan 4 pasien yang memiliki lama rawat yang lebih panjang yaitu $>6$ hari. Orsini et al. ${ }^{11}$ menyatakan pasien dengan komplikasi memiliki lama rawat yang lebih panjang yaitu 5-7 hari. ${ }^{11}$

Selain HELLP syndrome, DIC merupakan salah satu dari komplikasi berat yang dinyatakan berisiko 3-25 kali lipat dapat terjadi pada wanita dengan preeklamsia dan eklamsia. ${ }^{1}$ Penelitian
Kansaria dan Parulekar ${ }^{14}$ menyatakan bahwa terdapat 10 dari 52 pasien PEB dengan DIC sedangkan untuk eklampsia dengan DIC terdapat 8 dari 21 pasien eklamsia. ${ }^{14}$ Dalam penelitian ini ditemukan hanya ada 1 pasien (3\%) dengan DIC yaitu pada pasien eklamsia sedangkan pasien PEB dengan DIC tidak ditemukan.

Pada hasil penelitian dilihat berdasarkan penggunaan ventilator, sebagian besar pasien tidak memerlukan bantuan ventilator. Dari 11 pasien PEB $(33,3 \%)$ yang dirawat di ICU dan HCU, semuanya tidak menggunakan ventilator, sedangkan dari 22 pasien eklamsia, 17 pasien $(51,5 \%)$ tidak menggunakan ventilator dan hanya 5 pasien $(15,2 \%)$ yang menggunakannya. Hermanto et al. ${ }^{15}$ menyatakan bahwa terdapat 27 kasus preeklamsia-eklamsia yang dirawat di ICU dengan 22 kasus $(81,4 \%)$ memerlukan bantuan ventilator; 16 kasus (72\%) membutuhkan bantuan ventilator selama 48 jam. Shankar et al. ${ }^{17}$ menyatakan bahwa kasus gagal napas pada kehamilan salah satunya disebabkan oleh PEB/eklamsia dengan HELLP syndrome. Dalam penelitian ini, kelima pasien yang menggunakan ventilator, dilihat lama rawatnya berdasarkan komplikasi HELLP syndrome, ditemukan $4(80 \%)$ dari 5 pasien yang menggunakan ventilator merupakan pasien dengan komplikasi HELLP syndrome.

Telah diketahui bahwa pasien dengan preeklamsia dan eklamsia ini berisiko tinggi dalam menyebabkan kematian dan kecacatan baik bagi ibu maupun bayi. ${ }^{18}$ Penelitian Kansari dan Parulekar ${ }^{14}$ menyatakan bahwa dari 52 pasien PEB, 3 diantaranya meninggal dunia, sedangkan penelitian Ghike dan Asegaonkar ${ }^{19}$ menyatakan dari 9 pasien eklamsia di ICU terdapat 1 pasien yang meninggal. Pada penelitian ini, pasien PEB dan eklamsia yang dirawat di ICU dan HCU dari 33 pasien, 3 pasien $(9,09 \%)$ diantaranya meninggal dunia dimana semua pasien merupakan pasien eklamsia. Tinggi rendahnya angka kematian dapat dikarenakan pasien PEB dan eklamsia di ICU dan HCU mengalami komplikasi. 
Dari penelitian ini ketiga pasien yang meninggal, 2 diantaranya merupakan pasien eklamsia dengan HELLP syndrome.

\section{SIMPULAN}

Berdasarkan hasil penelitian dapat disimpulkan bahwa dari 33 total pasien terdapat 11 pasien PEB dan 22 pasien eklamsia dan yang terbanyak ialah usia $<25$ tahun dan lama rawat 1-2 hari.

Semua pasien PEB tidak mengalami komplikasi HELLP syndrome, sedangkan sebagian pasien eklamsia dengan HELLP syndrome dan memiliki lama rawat yang lebih lama. Terdapat 1 pasien eklamsia dengan komplikasi DIC.

Semua pasien yang menggunakan ventilator di ICU dan HCU merupakan pasien eklamsia dengan lama penggunaan terbanyak 1-4 hari dan sebagian besar mengalami komplikasi HELLP syndrome.

Angka kematian pasien $9,1 \%$ dan semuanya merupakan pasien eklampsia.

\section{SARAN}

1. Kelengkapan data rekam medik diperlukan untuk menunjang hasil yang lengkap, akurat, dan informatif.

2. Dapat dilakukan penelitian lebih lanjut dengan menambah waktu penelitian, variabel yang diteliti, dan penghitungan secara statistik agar mendapat hasil yang lebih bermakna.

\section{DAFTAR PUSTAKA}

1. Ghulmiyyah L, Sibai B. Maternal mortality from preeclampsia/eclampsia. Semin Perinatol. 2012;36:56-59.

2. Ross MG. Eclampsia. 2016 July 07. Available from: http://emedicine.medscape.com/article/ 253960-overview

3. Turner JA. Diagnosis and management of pre-eclampsia: an update. International Journal of Women's Health. 2010;2:327-37.

4. Shamsi U, Saleem S, Nishter $\mathbf{N}$. Epidemiology and risk factors of preeclampsia: an overview of observational studies. Al Ameen J Med Sci. 2013;6(4):292-300.

5. Khusen D, Polim AA. Factors influencing maternal mortality from severe preeclampsia and eclampsia. Indones $\mathbf{J}$ Obstet Gynecol. 2012;36(2):90-4.

6. Cunningham FG, Leveno KJ, Bloom SL, Hauth JC, Rouse DJ, Spong CY. Obstetri Williams volume 2 (23rd ed). Jakarta: EGC, 2010.

7. Kusuma TW, Affandi B, Ocviyanti D, Prihartono J. Manajemen risiko dalam pelayanan pasien preeklampsia berat (PEB)/eklampsia di Instalasi Gawat Darurat RSUPNCM. Maj Obstet Ginekol Indones. 2009;33(3): 135-42.

8. Djannah SN, Arianti IS. Gambaran epidemiologi kejadian preeklampsia / eklampsia di RSU PKU Muhammadiyah Yogyakarta tahun 2007-2009. Buletin Penelitian Sistem Kesehatan. 2010;13(4):378-85.

9. Yasmin F, Rashid M, Sultana MT. Emergence of Maternal Intensive Care Unit in Medical College Hospital. DinajpurMed Col J. 2013;6(1):97-99.

10. Guntupalli KK, Hall N, Karnad DR, Bandi $\mathbf{V}$, Belfort M. Critical llness in Pregnancy. Chest. 2015;148(4):10931104.

11.Atashkhoei S, Lame MM. Outcome of patients admitted to obstetric intensive care unit with severe preeclampsia, eclampsia or HELLP syndrome. Journal of Women's Health and Reproduction Sciences. 2015;3(3):156157.

12. Curiel-Balsera E, Prieto-Palomino MA, Mũ noz-Bono J, Elvira MJR, Galeas JL, García GQ. Analysis of maternal morbidity and mortality among patients admitted to Obstetric Intensive Care with severe preeclampsia. Med Intensiva. 2011;35(8):478-483.

13. Desalegn N, Haile M. Causes of Admission and out Comes among Preeclampsia and Eclampsia Mothers Admitted to Jimma University Specialized Hospital Intensive Care Unit. Clinical Medicine Research. 2015;4(5):154-9.

14. Kansaria JJ, Parulekar SV. Critical care in preeclampsia-eclampsia. Bombay Hospital Journal. 2008;50(1):19-25.

15. Hermanto, Adityawarman, Sulistyono, Ardian M, Dachlan EG. The characteristic of Indonesia's preeclampsia: From obstetric intensive care with ventilator until epidemiologic 
and its molecular biology profile of pulmonary edema in severe preeclampsia.

Pregnancy

Hypertens. 2014;4(3):245.

16.Zhang LN, Xiao YL, Wu TJ, Liu YJ, Wu DW. Clinical characteristics and outcomes of eclampsia patients admitted to the intensive care unit of China. Int J Chn Exp Med. 2016;9(4):7266-7267.

17. Shankar AK, Singh Y, Puri R, Tyagi A, Rohatgi S, Jagadish AM. Postpartum respiratory failure: case report. South Asian federation of obstetric and ginecology. 2010;2(1):73-5.

18.Jido TA. Eclampsia: maternal and fetal outcome. Afr health sci. 2012;12(2):148-52.

19.Ghike S, Asegaonkar P. Why obstetric patients are admitted to intensive care unit: retrospective study. Journal of South Asian Federationof Obstetric and Gynecology. 2012;4(2):90-2. 